\title{
Distribution of lymphoid neoplasm in eastern India: An experience from a tertiary care cancer research institute
}

\author{
Mala Mukherjee $^{1}$, Ajay Kumar ${ }^{2}$, Ashok Prasad ${ }^{3}$, Shatavisa Mukherjee ${ }^{4, *}$, Nikhil Era $^{5}$ \\ 1,2,3 Assistant Professor, ${ }^{1,2}$ Dept. of Pathology, ${ }^{3}$ Dept. of Microbiology, MGM Medical College and LSK Hospital, \\ Kishangunj, Bihar, ${ }^{4}$ Research Scholar, Dept. of Pharmacology, School of Tropical Medicine, Kolkata, West Bengal, ${ }^{5}$ Assistant \\ Professor, Dept. of Pharmacology, MGM Medical College and LSK Hospital, Kishangunj, Bihar, India
}

*Corresponding Author:

Email: shatavisa100@gmail.com

\begin{abstract}
Introduction: The classification of lymphoid neoplasm has witnessed significant revisions over the years with the recent one simplifying the diagnosis and management of lesions at the very initial stages of lymphomagenesis. Different subtypes of lymphoid neoplasm vary in the different geographical locations. The present study aimed to probe the distribution of lymphoid neoplasm in Eastern India.

Materials and Methods: A total of 79 cases of lymphadenopathy were included over a period of two years and were subjected to categorization according to WHO classification, using light microscopy and immunohistochemistry studies.

Results: Of the 79 cases of lymphadenopathy studied, 35 cases were NHL, 21 cases were HL and rest other types. The ratio of NHL to HL as per our study was 1.66:1. Among NHL cases B-cell lymphomas were the predominant type accounting for $77.78 \%$ of all NHL cases, while T-cell lymphomas constitute $17.78 \%$ cases. Among HL, mixed cellularity variant was the commonest type $(52.38 \%)$. followed by nodular sclerosis $(33.33 \%)$ and lymphocyte predominance $(9.52 \%)$.

Conclusion: While DLBCL was the most common prevalent B cell NHL subtype followed by follicular lymphoma, Burkitt's lymphoma and High Grade B Cell lymphoma, ALCL was the most common T-cell lymphoma subtype followed by peripheral T cell lymphoma and Mycosis fungoides. Mixed cellularity was found the most common subtype of HL followed by the nodular sclerosis.
\end{abstract}

Keywords: Hodgkin's lymphoma, Lymphoid neoplasm, Non-Hodgkin's lymphoma.

\section{Introduction}

The lymphomas are a heterogeneous group of disorders and accounts for up to $3 \%$ of all malignancies. The classification of lymphomas has undergone many changes over the last two decades. ${ }^{1}$ In 2001, the World Health Organization (WHO) produced a consensus classification encompassing immunophenotype, genetic abnormalities and clinical features. ${ }^{2}$ The 2008 WHO classification of hematopoietic and lymphoid tumors and the associated monograph represented the established guidelines for the diagnosis of malignant lymphomas; however, subsequently there were major advances with significant clinical and biologic implications, which led to a major revision in the nearly 8 -year-old classification of the lymphoid neoplasms. ${ }^{3}$ The 2016 WHO classification of mature lymphoid, histiocytic, and dendritic neoplasms thus clarified the diagnosis and management of lesions at the very early stages of lymphomagenesis, refined the diagnostic criteria for some entities, detailed the expanding genetic/molecular landscape of numerous lymphoid neoplasms and their clinical correlates, and referred to investigations leading to more targeted therapeutic strategies. $^{3}$

Non-Hodgkin lymphoma is the eighth leading cause of cancer death in the United States. NonHodgkin lymphoma is more common in men than women, and among individuals of Caucasian descent. According to SEER statistics of NHL, the number of new cases was 19.5 per 100,000 men and women per year, while the number of deaths was 5.9 per 100,000 men and women per year. These rates were however age-adjusted and based on 2010-2014 cases and deaths. ${ }^{4}$ As per 2012-2014 data, it is posed that approximately 2.1 percent of men and women will be diagnosed with non-Hodgkin lymphoma at some point during their lifetime. In 2014, there were an estimated 661,996 people living with non-Hodgkin lymphoma in the United States. The prognosis and treatment of NHL depend on the subtype, stage and associated comorbid conditions. While adequate information is available on the epidemiological profile of NHL from developed nations, such data is sparse from low middle income countries (LMICs) like India. The present study thus attempted to probe the distribution of various lymphoid neoplasms in a tertiary care Cancer institute in Eastern India.

\section{Materials and Methods}

The present study was a hospital based prospective research conducted in a dedicated tertiary care Cancer institute in Eastern India for a period of two years. Cases of enlarged lymphnodes were enrolled in the study. Those with metastatic and tubercular lymphadenopathy were excluded.

All patients with enlarged lymphnodes were subjected to fine needle aspiration cytology. Each patient with non-specific/inconclusive FNAC reports was subjected to lymph node excision biopsy. The cytology slides were prepared after aspiration and fixed. 
After fixation, the slides were stained with hematoxylin and eosin. The surgically biopsied lymph was fixed in $10 \%$ buffered formalin. After gross examination, entire or representative sections were taken followed by paraffin embedding, cutting and slide preparation and finally stained with hematoxylin and eosin. Both histopathology and FNAC slides were examined under light microscope.

Immunohistochemistry was performed according to avidin-biotin peroxidase complex method, after pretreatment of antigen retrieval, by heating in microwave oven in $0.01 \mathrm{M}$ citrate buffer (p H-6.0). The panel of immunohistochemistry (IHC) markers included CD45 (LCA), CD45RO, CD79, CD20, CD23, CD10, CD5, CD3, CD56, CD4, CD8, CD15, CD30, CD34, EMA, MUM1, BCL6, TdT, BCL2, MIB1/KI67, ALK1, Kappa and lambda light chains. The results were tabulated and recorded individually. (Fig. 1)
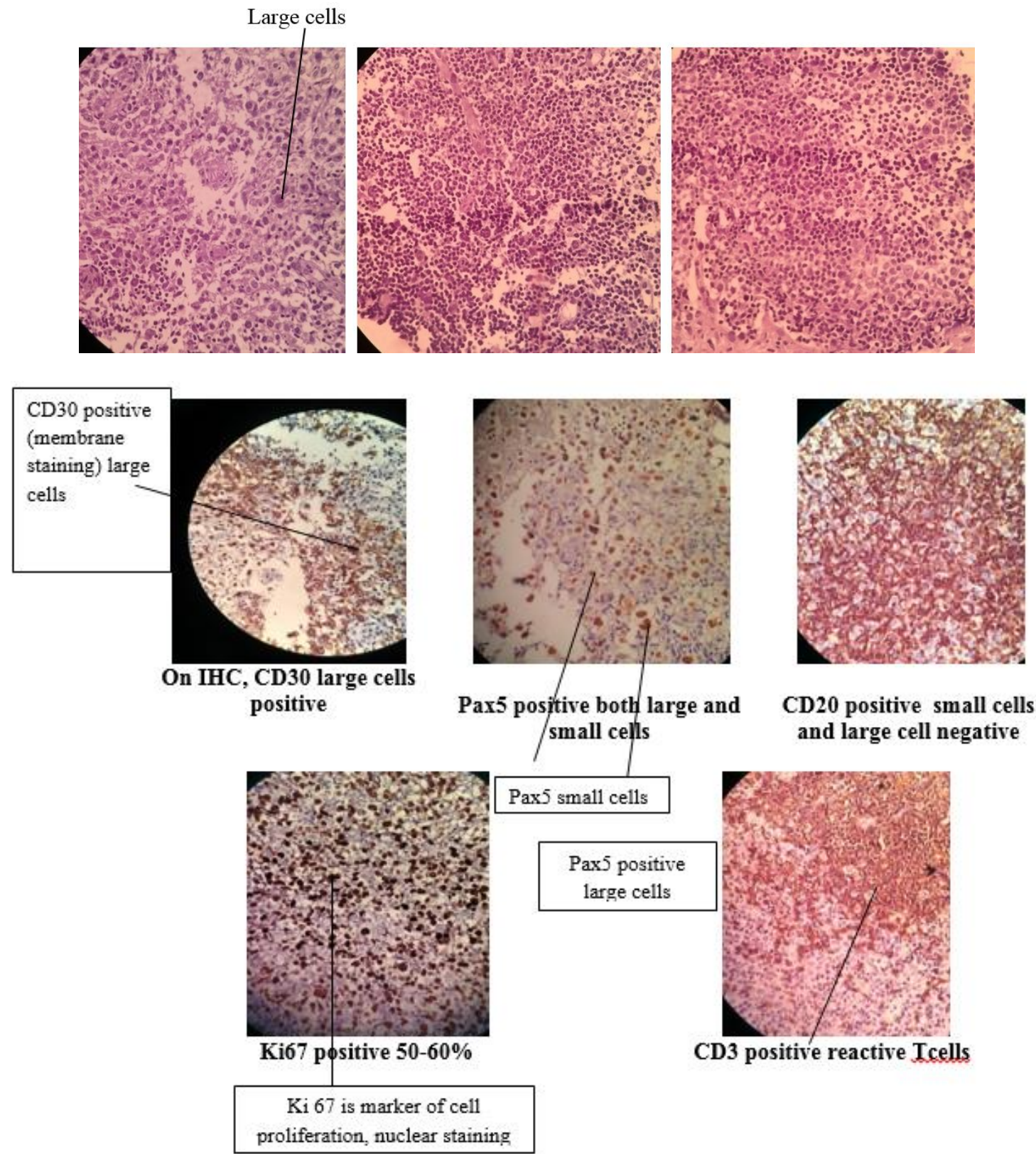

\section{CD20 positive small cells and large cell negative}

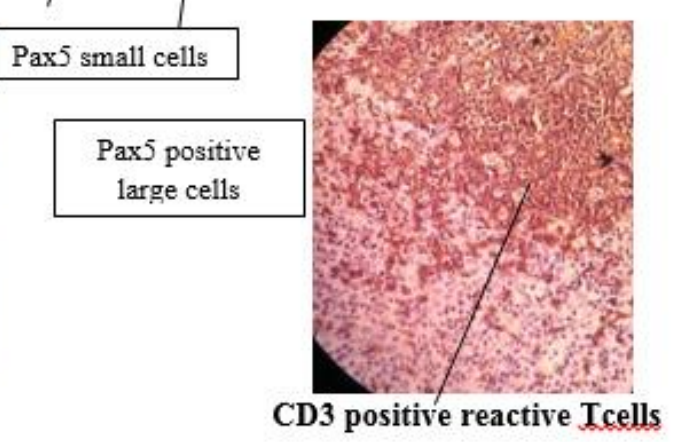

Fig. 1: Histopathological and immunohistochemistry presentations (Final diagnosis was confirmed by IHC as CD30 positive diffuse large $B$ cell lymphoma)

There was $100 \%$ concordance between the light microscopy and IHC studies.
All patients were subjected to routine hematological (estimation of hemoglobin, total, and different leucocyte count, platelet count, peripheral 
smear for abnormal/ blast cells etc.) and biochemical (liver function tests, urea, creatinine, uric acid) investigations. The radiological examination included chest radiograph, computed tomography, and ultrasonography of abdomen.

\section{Results}

Of the 79 cases of lymphadenopathy studied, 35 cases were NHL, 21 cases were HL and rest other types. (Table 1)

Table 1: Distribution of various causes of lymphadenopathy $(\mathrm{N}=79)$

\begin{tabular}{|l|c|c|c|}
\hline Causes of Lymphadenopathy & Frequency (\%) & Mean Age (Range) & Gender (M/F) \\
\hline NHL & $45(56.96)$ & $49.42(4-67)$ & $26 / 19$ \\
\hline HL & $21(26.58)$ & $43.5(5-61)$ & $15 / 6$ \\
\hline Atypical Lymphoid Hyperplasia & $06(7.59)$ & $40.66(32-51)$ & $4 / 2$ \\
\hline $\begin{array}{l}\text { Reactive Lymphoid } \\
\text { Hyperplasia }\end{array}$ & $05(6.33)$ & $54.33(45-63)$ & $4 / 1$ \\
\hline Meningoma & $01(1.26)$ & 53 & $1 / 0$ \\
\hline Adnexal Tumor & $01(1.26)$ & 38 & $0 / 1$ \\
\hline
\end{tabular}

NHL: Among 45 cases of NHL, 26 patients were males $(57.78 \%)$ and 19 were females $(42.23 \%)$. Male to female ratio was $1.36: 1$

The age range was 5-68 years with a mean age of 42.86 years. Among NHL cases B-cell lymphomas were the predominant type (35 cases) accounting for $77.78 \%$ of all NHL cases. T-cell lymphomas constitute 8 cases $(17.78 \%)$.

Of the B-cell neoplasms, diffuse large B-cell lymphoma (DLBCL) was the most common subtype (18 cases, $40 \%$ ), followed by follicular lymphoma (10 cases, $22.22 \%$ ). Among the follicular lymphomas, Grade 3 was most common type (6 cases), followed by
Grade 2 (3 cases) and Grade 1 (1 cases). Third common B-cell NHL was Burkitt's lymphoma (04 cases, 8.8\%) followed by High Grade B Cell lymphoma (02 cases, $4.44 \%$ ) and Plasmablastic lymphoma (01 case, 2.22\%). (Table 2)

T-cell lymphoma comprised of 8 cases $(17.78 \%)$ and anaplastic large cell lymphoma (ALCL) was the most common subtype (05 cases, $11.11 \%$ ), followed by peripheral $\mathrm{T}$ cell lymphoma (02 cases, 4.44\%), and Mycosis fungoides (01 cases, 2.22\%).

There were two cases of aggressive NK cell leukemia subtype. (4.44\%).

Table 2: Distribution of NHL $(\mathrm{N}=45)$

\begin{tabular}{|l|c|c|c|}
\hline \multicolumn{1}{|c|}{ Subtypes of NHL } & Frequency (\%) & Mean Age (Range) & Gender (M/F) \\
\hline B Cell Lymphoma & $18(40)$ & $47.81(30-59)$ & $10 / 08$ \\
\hline Diffuse Large Cell B Cell & $10(22.22)$ & $44.37(41-63)$ & $06 / 04$ \\
\hline Follicular Lymphoma & $04(8.88)$ & $9.25(5-13)$ & $02 / 02$ \\
\hline Burkitt's Lymphoma & $01(2.22)$ & 44 & $00 / 01$ \\
\hline Plasmablastic Lymphoma & $02(4.44)$ & $58.5(55-62)$ & $01 / 01$ \\
\hline High Grade B Cell Lymphoma & $05(11.11)$ & $23.36(12-26)$ & $03 / 02$ \\
\hline T Cell Lymphoma & $02(4.44)$ & $64(60-68)$ & $02 / 00$ \\
\hline $\begin{array}{l}\text { Anaplastic Large Cell } \\
\text { Lymphoma }\end{array}$ & $01(2.22)$ & 53 & $00 / 01$ \\
\hline Peripheral T Cell Lymphoma & $02(4.44)$ & $41.5(36-47)$ & $02 / 00$ \\
\hline Mycosis fungoides & \multicolumn{2}{|l|}{} \\
\hline NK Cell Lymphoma & Aggressive NK cell leukemia & \multicolumn{2}{|l|}{} \\
\hline
\end{tabular}

HL: Out of 21 cases of HL, 15 patients were males and 6 patients were females with a male-female ratio of 2.5:1. The age range for HL was 27-63 years with a mean age range of 31.3 years. All cases of $\mathrm{HL}$ were of nodal origin and no extra nodal case was detected in the study. The most frequent site was cervical group of lymph nodes (12 cases, $57.14 \%$ ) followed by axillary nodes (6 cases, 28.57\%), mediastinal nodes (2 cases, $9.52 \%$ ) and others. (Table 3)
Mixed cellularity variant was the commonest type (11 cases, 52.38\%). followed by nodular sclerosis (7 cases, $33.33 \%$ ) and lymphocyte predominance ( 2 cases, $9.52 \%)$.

Among the 7 cases of nodular sclerosis, five cases were Grade 1 and two cases were Grade 2. 
Table 3: Distribution of HL $(\mathrm{N}=21)$

\begin{tabular}{|l|c|c|c|}
\hline Subtypes of HL & Frequency (\%) & Mean Age (Range) & Gender (M/F) \\
\hline Classical Hodgkin's lymphoma & $11(52.38)$ & $39.56(28-63)$ & $8 / 3$ \\
\hline Classical mixed cellularity & $7(33.33)$ & $41.42(27-56)$ & $5 / 2$ \\
\hline Classical nodular sclerosis & $2(9.52)$ & $38.5(36-41)$ & $1 / 1$ \\
\hline Lymphocyte predominance & $1(4.76)$ & 55 & $1 / 0$ \\
\hline Nodular lymphocyte predominant & \multicolumn{3}{|l|}{}
\end{tabular}

\section{Discussion}

The classification of malignant lymphomas has witnessed significant revisions over the years with the recent one simplifying the diagnosis and management of lesions at the very initial stages of lymphomagenesis. However limited availability of the panel of IHC markers has posed a challenge to the investigations in resource constraint settings. Moreover geographical variations in lymphoid malignancies are also well known. In India, the first population based cancer registry was established in Mumbai by the Indian Cancer Society in $1964 .{ }^{5}$ Under the network of National Cancer Registry Program (NCRP) of Indian Council of Medical Research, other urban registries have been available in Delhi, Chennai, Bhopal and Bangalore. However, such registry data from Eastern India has been scare. The present study tried to probe the distribution of malignant lymphomas in a dedicated cancer research centre in Eastern India.

Our study investigated a total of 79 cases of lymphadenopathy of which 35 cases were NHL, 21 cases were HL and rest were cases of atypical lymphoid hyperplasia, reactive lymphoid hyperplasia, meningoma and adnexal tumor. The ratio of NHL to HL as per our study was $1.66: 1$ which is similar to another Indian study reporting $1.58: 1$ ratio. $^{6}$ Our study showed $26.58 \%$ ML cases to be HL, and appears to be in concurrence with studies from surrounding Eastern Mediterranean countries as well as other studies from India. ${ }^{7-14} \mathrm{~A}$ retrospective study involving 347 cases in Jordan revealed much higher percentage. ${ }^{15}$ On the contrary, much lower frequency of HL was seen in Asian countries like Japan $(7 \%),{ }^{16}$ Thailand $(8.5 \%),{ }^{17}$ and China $(6.6 \%){ }^{18}$

On studying the HL subtypes, mixed cellularity was found the most common subtype (52.38\%) followed by the nodular sclerosis subtype $(33.33 \%)$. Similar trend was found in Pakistan ${ }^{19}$ and also in one Indian study. ${ }^{6}$ However, in Jordan, Europe, USA and other western world, nodular sclerosis is the most common subtype. ${ }^{15}$ Increased incidence of mixed cellularity subtype in and around Indian subcontinent may be due higher risk of childhood exposure to Epstein Barr virus that is more likely to be associated with a mixed cellularity than nodular sclerosis. ${ }^{20}$ Mixed cellularity as well as nodular sclerosis was more prevalent in males than females. Studies in Western Ethiopia of Africa reported lymphocyte predominant subtype as the common type of HL. ${ }^{21}$
Our study showed $56.96 \%$ of the cases as NHL. Of NHL subtypes, our study revealed DLBCL as the most common prevalent subtype (40\%). DLBCL has also been reported to be the most common NHL in most studies worldwide, but it varies considerably from region to region..$^{22}$ The percentage of DLBCL noted in the current study is much in concurrence with other Indian studies reporting the figures to be $33-37 \%$, 23,24 However the figures are quite higher as in Pakistan $66.1 \% .{ }^{19} \mathrm{UAE}$ at $59 \%,{ }^{10}$ Northern Iraq $52.2 \%,{ }^{14}$ Kuwait $47.6 \%,{ }^{25}$ Egypt $49 \%,{ }^{24}$ Jordan $43.8 \%-53 \%,{ }^{15,26}$ and Turkey at $41 \% .{ }^{27}$

Follicular lymphomas were the second most common subtype of NHL (22.22\%) in our study, which is comparable in other Indian study. ${ }^{23} \mathrm{~A}$ higher proportion is noted in Western studies (28-32\%). Lower incidence of follicular lymphoma (4-8\%) was reported from Saudi Arabia, Egypt, UAE, North Jordan and Pakistan. ${ }^{10,14,19,24,26}$ Among the follicular lymphomas, Grade 3 was most common type, followed by Grade 2 and Grade 1 respectively. Low rates of follicular lymphoma in developing countries might be due to the fact that many DLBCL progresses from previously undiagnosed follicular lymphoma and those unique environmental or genetic factors may contribute to such progression. ${ }^{23}$ Third common B-cell NHL was Burkitt's lymphoma $(8.8 \%)$ followed by High Grade B Cell Lymphoma $(4.44 \%)$ and Plasmablastic lymphoma (2.22\%). T-cell lymphoma comprising of $17.78 \%$ of NHL cases revealed ALCL as the most common subtype $(11.11 \%)$, followed by peripheral $\mathrm{T}$ cell lymphoma (4.44\%), and Mycosis fungoides (2.22\%). Our study noted two cases of aggressive NK cell leukemia subtype. However, the small study sample size posed to be the main limitation for the study.

\section{Conclusion}

The present study revealed the ratio of NHL to HL being 1.66:1. Of the HL subtypes, mixed cellularity was found the most common subtype followed by the nodular sclerosis. DLBCL was the most common prevalent B cell NHL subtype followed by follicular lymphoma, Burkitt's lymphoma and High Grade B Cell lymphoma. ALCL as the most common T-cell lymphoma subtype followed by peripheral $\mathrm{T}$ cell lymphoma and Mycosis fungoides.

\section{Source of Funding: None}

Conflict of Interest: None. 


\section{References}

1. Nair R, Arora N, Mallath MK. Epidemiology of NonHodgkin's Lymphoma in India. Oncology. 2016;91(suppl 1):18-25.

2. Vardiman JW, Thiele J, Arber DA, Brunning RD, Borowitz MJ, Porwit A et al. The 2008 revision of the World Health Organization (WHO) classification of myeloid neoplasms and acute leukemia: rationale and important changes. Blood. 2009;114(5): 937-951.

3. Swerdlow SH, Campo E, Pileri SA, Harris NL, Stein H, Siebert R et al. The 2016 revision of the World Health Organization classification of lymphoid neoplasms. Blood. 2016;127(20):2375-2390.

4. Cancer Stat Facts: Non-Hodgkin Lymphoma. Accessed from https://seer.cancer.gov/statfacts/html/nhl.html. Accessed on June 13, 2018.

5. Yeole BB. An Assessment of Improvement in Reliability and Completeness of Mumbai Cancer Registry Data from 1964-1997. Asian Pac J Cancer Prev. 2001;2(3):225-232.

6. Chakrabarti S, Sarkar S, Goswami BK, Mondal S, Roy A, Das S. Hodgkin's and Non-Hodgkin's lymphomas in an Indian rural medical institution: Comparative clinicopathologic analysis. Asian Pac J Cancer Prev. 2010;11:1605-8.

7. Mondal SK, Mandal PK, Roy SD, Chattopadhyay S, Roy S, Biswas PK. Malignant lymphoma in Eastern India: A retrospective analysis of 455 cases according to World Health Organisation classification. J Can Res Ther. 2014;10:354-8.

8. Bamanikar S, Thunold S. Devi KR, Bamanikar A. The pattern of malignant lymphoma in Oman. J Trop Med Hyg. 1995;98:351-4.

9. Mahboubi E. Epidemiology of cancer in Saudi Arabia. Ann Saudi Med. 1987;7:265-76.

10. Castella A, Joshi S, Raaaschou T, Mason N. The pattern of malignant lymphoma in united Arab Emirates: A histopathologic and immunologic study in 208 native patients. Acta Oncol. 2002;40:660-4.

11. Shome DK, George SM, Al-Hilli F, Satir AA. Spectrum of malignant lymphomas in Bahrain. Leitmotif of a regional pattern. Saudi Med J. 2004;25:164-7.

12. Hashemi-Bahremani M, Parwaresch MR, Tabrizchi H, Gupta RK, Raffii MR. Lymphoma in Iran. Arch Iran Med. 2007;10:343-8.

13. Patkar N, Mehta J, Kulkarni B, Pande R, Advani S, Borges A. Immunoprofile of Hodgkin's Lymphoma. Indian J Cancer. 2008;45:59-63.

14. Yaqo RT, Hughson MD, Sulayvani FK, Al-Allawi NA. Malignant lymphoma in northern Iraq: A retrospective analysis of 270 cases according to the World Health Organizatio n classification. Indian J Cancer. 2011;48:446-51.

15. Haddadin WJ. Malignant Lymphoma in Jordon: A retrospective analysis of 347 cases according to the World Health Organization classification. Ann Saudi Med. 2005;25:398-403.

16. Aoki R, Karube K, Sugita Y, Nomura Y, Shimizu K, Kimura Y, et al. Distribution of malignant lymphoma in Japan: Analysis of 2260 cases, 2001-2006. Pathol Int. 2008;58:174-82.
17. Sukpanichnant S, Sonakul D, Piankijagum A, Wanachiwanawin W, Veerakul G, Mahasandana C, et al. Malignant lymphoma in Thailand: Changes in the frequency of malignant lymphoma determined from a histopathologic and immunophenotypic analysis of 425 cases at Siriraj Hospital. Cancer. 1998;83:1197-204.

18. Yin HF, Li T, Li Jx. Retrospective analysis of 304 cases of malignant lymphomas in pathology: Study and practice of the WHO classification of lymphoid neoplasms. Zhonghua Yi Xue Za Zhi. 2003;83:1556-60.

19. Htaq S, Akhtar N, Jamal S, Mamoon N, Khadim T, Sarfaraz T, et al. Malignant lymphomas in Pakistan according to the WHO classification of lymphoid neoplasms. Asian Pac J Cancer Prev. 2008;9:229-32.

20. Al-Diab AI, Siddiqui N, Sogiawalla FF, Fawzy EM. The changing trends of adult Hodgkin's disease in Saudi Arabia. Saudi Med J. 2003;24:617-22.

21. Getachew A. Malignant lymphoma in western Ethiopia. East Afr Med J. 2001;78:402-4.

22. Anderson JR, Armitage JO, Weisenburger DD. Epidemiology of the non-Hodgkin's lymphomas: Distributions of the major subtypes differ by geographic locations. Non-Hodgkin's Lymphoma Classification Project. Ann Oncol. 1998;9:717-20.

23. Naresh KN, Srinivas V, Soman CS. Distribution of various subtypes of non-Hodgkin's Lymphoma in India: A study of 2773 lymphomas using R.E.A.L and WHO Calssifications. Ann Oncol. 2000;11 (suppl 1):63-7.

24. Naresh KN, Agarwal B, Nathwani BN, Diebold J, Mclennan KA, Muller-Hermlink KH, et al. Use of World Health Organization (WHO) classification of NonHodgkin's Lymphoma in Mumbai, India: A review of 200 consecutive cases by a panel of five expert haematopathologists. Leuk Lymphoma. 2004;45:1569-77.

25. Temmim L, Baker H, Al- Jarallah M, Manguno H, Madda JP, Sinowatz F. Clinical characteristics and pathological classifications of non-Hodgkin's lymphoma in Kuwait. Results of a collaborative with the International Lymphoma Study Group (ILSG). Leuk Lymphoma. 2004;45:1865-71.

26. Almasri NM, Habashneh MA, Khalidi HS. Non-Hodgkin lymphoma in Jordan. Types and patterns of 111 cases classified according to the WHO classification of hematological malignancies. Saudi Med J. 2004;25:60914.

27. Isikdogan A, Ayyildiz O, Buyukcelik A, Arslan A, Tiftik $\mathrm{N}$, Buyubayram H, et al. Non-Hodgkin's lymphoma in southeast Turkey: Clinicopathologic features of 490 cases. Ann Hematol. 2004;83:265-9.

How to cite this article: Mukherjee M, Kumar
A, Prasad A, Mukherjee S, Era N. Distribution
of lymphoid neoplasm in eastern India: An
experience from a tertiary care cancer research
institute. J Diagn Pathol Oncol. 2018;4(3):172-
176.

